\title{
Understanding suicide among indigenous adolescents: a review using the PRECEDE modet
}

\author{
Valerie A Clarke, C James Frankish, Lawrence W Green
}

\begin{abstract}
Aim-To use the available literature to identify the causes of suicide among indigenous adolescents.
\end{abstract}

Method-The PRECEDE model provided a framework to organize the material and identify the areas where relatively little research had been reported.

Results-The epidemiological diagnosis showed that suicide was greater in indigenous than non-indigenous populations and particularly high among adolescent males. Environments of native persons are characterized by remoteness, poverty, cultural displacement, and family disintegration. The educational and organizational diagnosis identified predisposing factors reflecting the social environments previously identified, the enabling factors of televised suicides, and firearm and alcohol availability, in conjunction with an absence of positive expectations. Finally the administrative and policy diagnosis identified a piecemeal, short term perspective, often lacking cultural sensitivity. Although there was more literature from the United States than from Canada, Australia or New Zealand, the pictures emerging were consistent, with problems being identified across continents. Literature was more abundant in relation to the epidemiological, environmental, and educational/organizational diagnoses than in relation to policy and administration.

Conclusion-The increased suicide rates among indigenous adolescents were not a product of their native origins, but of the social milieu in which these people generally found themselves.

(Injury Prevention 1997; 3: 126-134)

Keywords: suicide; indigenous adolescents; PRECEDE model.

Most reviews of intentional injuries in aboriginal populations have focused on specific groups such as the Navajo Indians, ${ }^{1}$ Hopi Indians, ${ }^{2}$ or Australian Aboriginals. ${ }^{3}$ Some focus more specifically on suicide among American Indian adolescents, ${ }^{4}$ or on one aspect of the broader problems underlying intentional injury, such as epidemiological analyses, ${ }^{5}$ alcohol abuse, ${ }^{6}$ or drug abuse. ${ }^{7}$ A few have addressed interventions related to specific problems. However, there has been little systematic attempt to provide an overview of the literature pertaining to suicide among indigenous adolescents. These people share the common characteristic of being young members of a minority culture which predate the arrival of the Anglo-Saxon population in their homeland. Although native to different5 continents, they are likely to share commoA concerns. An integrative analysis examining data from across different populations faciitates the identification of common themes. ${ }^{8}$

The aim of this paper is to integrate the available literature, organizing it within $\vec{D}$ planning and evaluation framework. The use of this framework facilitates the identification of areas where there has been limited research The primary focus of the paper is on native adolescents-the group that is most likely to commit suicide. The review aims to provide a overview of relevant issues and to identify those needing further attention, acknowledging lims itations of generalizability.

\section{Definitions}

Suicide occurs when an individual takes his/her own life-it is literally self murder. ${ }^{9}$ Parap suicide involves a person giving the impressio of attempting to take his/her own life. The territ 'parasuicide' is used in preference to the term 'attempted suicide', as many researchers be lieve that the intention of a parasuicide is noit always to take their life, but often to make $\frac{\pi}{9}$ plea for help. ${ }^{10}$ In some cases, identification of suicides among aboriginal populations may be problematic.

\section{The PRECEDE-PROCEED model}

PRECEDE-PROCEED ${ }^{11}$ is a conceptua model for planning health education and health promotion programs and policies (see figure). The PRECEDE model provides a wey tested means of articulating a program plaft and rationale; and a means of documenting systematic, step-by-step approach to planning implementing, and evaluating suicide relate programs and policies.

The PRECEDE provides a framework with in which to identify and address the factors underlying any health related problem. The PRECEDE part of the model is read from righen to left, starting with the quality of life, while the PROCEED part of the model is read from left to right. PRECEDE deals with diagnosis of the problem and development of a program plan, while PROCEED is concerned with program 
PRECEDE-PROCEED MODEL

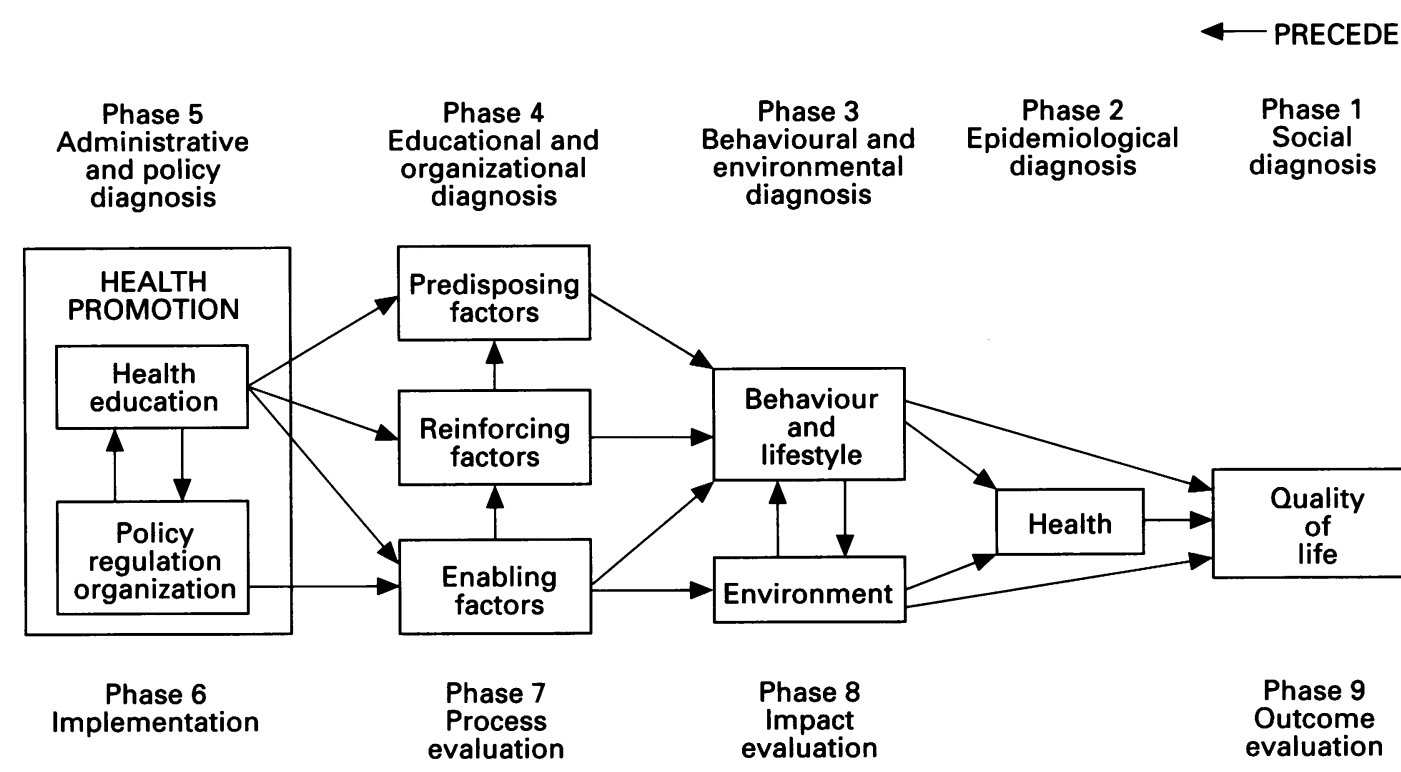

PROCEED $\longrightarrow$

The PRECEDE-PROCEED model. Reproduced, with permission, from Health Promotion Planning: An Educational and Environmental Approach by $L$ Green and M Kreuter; published by the Mayfield Publishing Company, 1991.

implementation and evaluation. The PRECEDE part of the PRECEDE-PROCEED model was selected as the organizing framework for this review. The model has been widely applied, with over 500 published applications in the literature. ${ }^{12-18}$ It was developed in the 1970s in a series of clinical and field experiments at Johns Hopkins University, then used in the development of the health promotion objectives for the nation in the United States, the Canadian Health Promotion Survey, and other national and regional programs. It was compared statistically in a prospective study of change in health behaviours with several other behavioural models and was found to account for a larger proportion of the variance in the behaviours than the other models, including Azjen and Fishbein's theory of reasoned action ${ }^{19}$ and the health belief model. ${ }^{2021}$ It has been applied in injury control $^{12}$ and in suicidology. ${ }^{22}$

In brief, the model suggests that the initial focus should be on social diagnosis, or quality of life, of the people who are the focus of the analysis. At stage two, the epidemiological diagnosis assesses the incidence of the problem (suicide) to establish the scope of the mortality and morbidity and to identify segments of the population where the problem is greatest. The behavioural and environmental diagnosis is concerned with identifying aspects of the physical, cultural, and socioeconomic environments and lifestyle factors that might contribute to suicide. Stage four is concerned with the educational and organizational factors that predispose certain individuals to consider suicide, the elements in the social environment that reinforce these behaviours, and those elements that enable the development of these predispositions. At stage five, the focus is on administrative and policy issues that might inhibit or facilitate programs-services and conditions needed to bring about changes in the lifestyle or environmental factors. Once all of these analyses have been completed, and the essential changes required to influence suicide have been identified for a specific population, interventions can be implemented.

\section{Situational analysis and social diagnosis}

The first phase of the model involves a situational analysis and social diagnosis. The situational analysis is used to describe the demographic, social, economic, and environmental conditions in a particular community. The social diagnosis phase of the model focuses on social, economic, and environmental costs of health problems and their consequent impact on quality of life. The identification of specific health problems or behaviours (for example, suicide) as a concern or quality of life issue provides the motivation for change through a programmed intervention or action by community members, groups, or organizations. Data on suicide rates examined in an epidemiological diagnosis must be viewed within the context of quality life concerns for their citizens and consider the social, political, and environmental contexts and the living conditions of residents.

\section{Epidemiological diagnosis}

The purpose of the epidemiological diagnosis is ultimately to use inferences from available or estimated data to prevent disease and promote health and wellbeing. Community members (aided by researchers) should examine the available data or evidence on the prevalence 
and distribution of mortality, morbidity, and related health outcomes. They should also examine the relationship of suicide to issues raised in the social diagnosis of their community. Long term objectives for suicide related programs and policies should flow from these first two phases.

The epidemiological diagnosis has three purposes: it provides empirical support for addressing a priority health problem (for example, suicide); it illustrates the magnitude of specific health problems; and finally, it results in the specification of concrete health objectives. The epidemiological diagnosis also consists of three phases: assessing the prevalence, incidence, and distribution of data on identified health problems; comparison of identified health issues or public health problems; and the setting of health objectives.

The population of Canadian Registered Indians, Australian Aboriginals, and New Zealand Maoris are similar, being 251000 , 228000 , and 296000 respectively whereas the American Indian population is 1.3 million. In each case, the populations are relatively young with at least $50 \%$ being less than 25 years and only $5 \%$ older than 65 years. ${ }^{8}$

Suicide rates for American Indians are 1.5 to 1.7 times greater than those for the nation. Statistics comparing suicide rates among $\mathrm{Na}$ tive American tribes with those of the general population draw inconsistent conclusions because the global rates mask the great variability among tribes. ${ }^{23-25}$ Whereas the suicide rate of 11.8 per 100000 among the Navajo is close to the national average, rates are as low as eight per 100000 on some reservations and as high as 43.3 per 100000 among the Apache. ${ }^{46-28}$

The suicide rate of indigenous Canadians has been shown to be three times higher than in the general population. ${ }^{29}$ In British Columbia it is 13.5 per 100 000; while for Status Indians in British Columbia it is 48.8 per $100000 .^{30}$

There has been a threefold increase among adolescents. ${ }^{31}$ For example, for American Indians aged 10-14 years, the suicide rate is 2.8 times the national rate, for $15-19$ years it is 2.4 times the national rate, and for 20-24 years it is 2.3 times the national rate. British Columbia statistics for 1989 show that for the total population there were 412 suicides of which $20 \%$ occurred in persons under the age of 25 years; for Status Indians there were 36 suicides of which $42 \%$ occurred among persons under $25 .{ }^{30}$

On a Hopi Indian reservation $80 \%$ of suicides occurred among those aged 15-24 years. ${ }^{2}$ For New Zealand Maoris, the suicide rate for males aged 15-24 peaked in 1989 at 49.0 per 100000 and for females peaked in 1986 at $17.3 .^{32}$ Similar patterns occur among the Australian Aborigines, ${ }^{33-40}$ and indigenous people in the Northwest Territories. ${ }^{41}$ Native suicide rates among the 15-24 year age group are increasing at a faster rate than any other age group. ${ }^{23}$

The different age distributions in indigenous and non-indigenous populations partly explain the apparently higher suicide rates among native people when statistics are not age adjusted. Not only are suicides concentrated among the younger age groups in these populations, but a higher proportion of the population falls into this age group. Fot example, the average age of the American population is 29.5 years, while the average age of the Native Indian population is 17.3 years. However, even when age adjusted rates are considered, suicides among indigenous per $\frac{0}{0}$ sons remain consistently higher than those among non-indigenous persons, especially among males aged $15-24$ years. ${ }^{42}$

Suicide is more common among males than among females. For example, in British Col? umbia there are clear sex differences, with $\vec{a}$ male suicide rate of 20.8 per 100000 and a

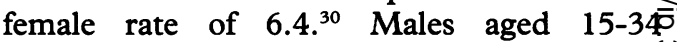
accounted for $64 \%$ of all Native American suicides from 1979-92. ${ }^{43}$ These sex differencesare also apparent in localized studies. ${ }^{44} \mathrm{~A}$ studyo of adolescent suicides in Newfoundland ance Labrador showed that males were five timesmore likely to commit suicide than females. ${ }^{4}$ है However, the disparity between male ando female suicide rates may decline with more women entering the workforce, as suicide? among Native American women positivelye correlates with the percentage of women in the workforce. ${ }^{4647}$

For each suicide, there are between 50 andi 150 parasuicides. $^{31} 48$ It has been suggested that as many as $15 \%$ to $17 \%$ of indigenous high school students ${ }^{49} 50$ have made at least one suicide attempt and suicidal ideation is sig nificantly higher among indigenous than non? indigenous adolescents. Suicidal ideation and parasuicide are frequently precursors to sui cide. ${ }^{51-54}$

Reported suicide rates may be an under estimate of the true incidence of suicide due to misclassification: (1) many deaths which the medical examiner classifies as motor accident? may be suicides ${ }^{28}{ }^{55}$; (2) many deaths classified as homicide may be homicide induced suif cides; (3) suicides among natives may be under-reported due to cultural and religious taboos $^{2}$; and (4) medical files are often? incomplete, not stating the cause of death ing cases that may be suicides. It has been estimated that under-reporting could be as great as $58 \% .^{45} 56-58$

Thus, there is extensive epidemiological dat documenting the numbers of suicides nation? ally and in small local areas. Although there is considerable variability across tribes or sub cultural groups, there is a consistency across ${ }^{5}$ continents indicating that suicide rates are higher among indigenous than non-indigenous persons, especially among male adolescents.

Behavioural and environmental diagnosio In the phase following the epidemiologicap diagnosis, program planners and policy makeres should attempt to identify controllable of preventable factors related to suicide. These should be assessed to identify those that deserve priority. Program planners must examine the relations among lifestyle, behaviour, 
environment, and suicide as identified in the epidemiological diagnosis. In the behavioural and environmental diagnosis, the possible 'channels for change' in suicidal behaviours are identified. These may be conceptualized as individual, lifestyle, and environment. Lifestyle factors are in many ways the linchpin which link the individual to his or her environment. Environmental factors may include non-behavioural, physical hazards, or conditions.

\section{BEHAVIOURAL DIAGNOSIS}

A variety of means for committing suicide are used and differences exist across indigenous populations. Among Canadian Indians, the most frequent means of committing suicide are firearms and drugs, while among the Inuit they are hanging and firearms. ${ }^{29}$

\section{ENVIRONMENTAL DIAGNOSIS}

Environments are considered by examining their cultural, physical, and socioeconomic aspects and their implications for lifestyles of indigenous adolescents. Consideration of such factors provides the context for adolescent suicide. Data on various factors existing in the cultural, physical, and socioeconomic environment provide some evidence as to the potential strength of their relations to adolescent suicide. Because adolescents are profoundly affected by their parents and families, the following section(s) examine environmental factors for the overall family constellation.

\section{CULTURAL ENVIRONMENTS}

The role of cultural integration as a cause of suicide was first recognized in 1897 by Durkheim who noted that suicide rates varied inversely with the degree of integration into social groups. ${ }^{59-64} \mathrm{~A}$ lack of social integration occurs frequently among indigenous persons whose traditional culture has been disrupted. ${ }^{65}$ Such disintegration is more common among those tribes who have been deprived of their traditional means of livelihood: in hunting and traditionally warrior tribes confined to reservations. ${ }^{66}$ The similarity of suicide rates between Navajo and Apache tribes is consistent with this interpretation. As a result of the breakdown in tribal traditions, adolescents experience a lack of identity as they are no longer part of an integrated tribal culture nor are they part of the mainstream culture. Lack of identity leads to feelings of isolation. These feelings of social isolation are exacerbated by pressures to succeed in the alien Anglo-Saxon community. Those who succeed in either the academic or sporting arena in mainstream society may be rejected by their tribe for failing to adhere to the norm of anonymity. ${ }^{46667}$

The role of cultural factors is demonstrated in a study of the Wind River tribe, where nomadic buffalo hunters were forced to become farmers and ranchers. ${ }^{68}$ During 1985 , the suicide rate temporarily reached a high of 300 in 100000 in what has become known as a suicide epidemic. Adolescents already experiencing a conflict between their childhood and adult roles faced additional stresses: (1) Indian male adolescents were isolated, being victims of prejudice by the white community and devoid of an Indian cultural background; (2) the Indian cultural norm of presenting a passive, composed exterior, prompted a major conflict between the inner turmoil and the presented public persona; (3) high unemployment and poor living conditions led to hopelessness; and (4) due to the small numbers in the community and the interconnectedness of the population, any suicide served as a role model for others.

Changes to traditional marriage patterns create further stresses. Changes in the tribal structure of the Hopi Indians have led to an increased tendency for marriages to occur outside the tribe. Individuals in such marriages often become disassociated from their tribe leading to a lack of the social support usually provided by the family and tribe. Children of these marriages can become culturally disinherited, leaving them too without social support. ${ }^{69}$ Similarly, children who are adopted often become culturally dispossessed, especially at adolescence, when they discover that they are not accepted by the adopting Anglo community and have lost all ties with their tribal community. ${ }^{40}$ Thus, in psychological terms, the cultural environment increases the problem for native adolescents, in that they experience the conflict of identity versus role confusion in two arenas ${ }^{71}{ }^{72}$ : (1) as adolescents between the worlds of childhood and adulthood; and (2) as natives between the tribal culture and the mainstream culture.

\section{FAMILY ENVIRONMENT}

Suicide has been described as being the product of a three stage process: (1) a history of problems throughout childhood and adolescence; (2) escalation of the problems during adolescence; and (3) a rapid breakdown of contacts with family and peers leading to social isolation. ${ }^{34} 355173$ Families contribute to suicide through their contribution to the level of stress experienced by the adolescent and their failure to provide social support. ${ }^{74}$ Given that the majority of indigenous suicides are among adolescents, the role of the family environment may be more crucial in these groups than among Caucasians. ${ }^{75}$

Studies focusing on different native populations are consistent in showing that those who commit suicide differ from those who do not in that they are more likely to have: (1) lost one or both parents through death, divorce, or separation $^{4}{ }^{9}{ }^{76}$; (2) had more diverse caretakers ${ }^{76}$; (3) adoptive or foster child status ${ }^{44}$; (4) experienced physical or sexual abuse ${ }^{4}$; (5) lack social support of immediate family members ${ }^{92} 54$ 74; (6) have immediate family members or close friends who have committed suicide ${ }^{44}$; (7) are concerned about parental drug use ${ }^{53}$; and (8) generally experience increased levels of family disruption. ${ }^{51}$

Similarly, difficulties with school are more 
common among natives who commit suicide. They are more likely to have: (1) poor school records ${ }^{10}{ }^{19}$; (2) attended a boarding school ${ }^{77}$; (3) not liked school ${ }^{52}$; or (4) been transferred to a large school with its associated anonymity and removal from their adolescent peer group. ${ }^{4}$ Among American Indian and Alaskan Native adolescents in boarding schools, depression and related problems are common. ${ }^{77-79}$

PHYSICAL AND SOCIOECONOMIC ENVIRONMENTS

The lands allocated to reservations, whether in the United States, Canada, or Australia are generally the more remote and least economically viable and unwanted areas. ${ }^{80-82}$ As a consequence, indigenous communities are frequently characterized by many of the features that are common to remote rural communities including isolation; geographical distance; limited communication; high levels of self treatment; self reliant attitudes towards health; anti-intellectual attitudes; a strong sense of community; and poverty. ${ }^{7628384}$ The physical environment has a major impact on social and economic opportunities. ${ }^{85-88}$

The role of the economic climate in suicide was recognized by Durkheim when he argued that suicide rates increase in times of economic recession and decrease in times of prosperity and war. $^{89}$ The relationship between socioeconomic factors and suicide has been documented. Suicide relates to unemployment ${ }^{59}{ }^{84}$; lower socioeconomic status ${ }^{18488}$; a high incidence of financial concerns ${ }^{68}$; northern latitude (in the northern hemisphere) ${ }^{84}$; and distance from the nearest town. ${ }^{84}$ During times of economic recession there is little opportunity for work, leading to feelings of helplessness and hopelessness that are alleviated by alcohol and drugs. ${ }^{52}{ }^{90-93}$ Girls may have some incentive to become unwed mothers as this leads to an increase in their welfare payments. In these cases, the resolution of one problem creates another. Children living in poverty or those whose families have recently been unemployed are more likely to be abused and to develop a low self esteem. ${ }^{84}$ 94-97

As a result of these socioeconomic conditions, many adults have spent their entire life living on welfare and are unfamiliar with alternatives, seeing little need to work for wages when they are receiving money for not working. ${ }^{98}$ Living on welfare leads to the development of feelings of hopelessness, which are often alleviated by resorting to alcohol and other drugs that are, in turn, precursors of increased risk for suicide. ${ }^{99}$

The economic position of indigenous persons is evident from a consideration of unemployment rates. Estimates of Indian unemployment range from $35 \%$ to $75 \%$ of the labour force. ${ }^{100}$ It is claimed ${ }^{101}$ that any assessment of socioeconomic conditions leads to the conclusion that the Canadian Native Indians are the most destitute group in Canada, with $75 \%$ living below the 'poverty line'. They earn $21.3 \%$ of the Canadian average wage, $25 \%$ have no formal schooling, and $70 \%$ are unemployed-10 times the national average.

Indians living on reserves had an employment rate of $28.2 \%$ compared with a rate of $36.8 \%$ for off-reserve Indians. In $1986,28.2 \%$ of Indians living on reserves had never worked for wages. When these people are employed, they tend to be in the hardest, most menia毒 and/or lowest paid jobs. ${ }^{102}$ Relative to the general population, Canadian Indians in urbaf areas also have a lower level of formal educa tion, a higher rate of unemployment, a greatê dependence on welfare, and are more fres quently transient. Indigenous city dwellers face jurisdictional difficulties, often falling down the cracks between the relevant support service and authorities. ${ }^{85} 86103$

There may be sex differences in the role economic factors in suicide, with males being more affected by unemployment. In the gen eral population, the relationship between the suicide rates and unemployment rates Australia for the period 1907-90 showed that female suicide rates were relatively constans, while male rates fluctuated with unemployt ment levels, the relationship being strongest $\overrightarrow{0}$ 15-24 year old males. ${ }^{104}$

Educational and organizational diagnosis 총 The division of determinants of outcomes in predisposing, enabling, and reinforcing facto usefully organizes the planning of potential interventions according to the previously idery tified major channels of influence (individuat lifestyle, environment) that can be mobilized for change. These categories are defined Green and Kreuter as follows:

Predisposing factors include knowledge, at tudes, beliefs, values as antecedents to suicida behaviour that provide the rationale or motiv tion for behaviour.

Reinforcing factors include social suppor behaviour of peers, caregivers, professionals and significant others. These factors subses quent to (attempted suicidal) behaviour prơ vide the continuing reward or incentive for the behaviour and contribute to its persistence of repetition.

Enabling factors include skills, availabili and accessibility of resources. They are ante cedents to (suicidal) behaviour that enable motivation to be realized.

\section{PREDISPOSING FACTORS}

The suicide decision is rarely impulsive. Oftêf adolescents have considered suicide and have developed a plan over a long period of time, boi the actual implementation of the plan may be triggered by a single event, ${ }^{31}$ such as a break-up with a partner. ${ }^{44}$ In many cases, suicides occur in 'clusters' with the suicide of an adolesce? native male triggering other suicides in the immediate area. ${ }^{105-108}$ Many researchers hav also attempted to identify personality or fami characteristics associated with suicide. Indigenous adolescents who commit suicide frequently have: (1) made previous suicide attempts $^{52-54}$; (2) a history of mental ill- 
ness, ${ }^{5054}$, especially depression ${ }^{23}$ 78-79 109; (3) one or more emotional problems requiring professional help ${ }^{50}$; (4) low self esteem resulting from chronic illness or disease ${ }^{4}$; (5) feelings of hopelessness and stress ${ }^{52}$; (6) high levels of interpersonal conflict ${ }^{54}$; (7) poor interpersonal communication skills ${ }^{52}$; (8) dependence on others $^{23} 4977110$; (9) an inability to delay gratification ${ }^{9}{ }^{10} ;(10)$ caused a pregnancy; and used alcohol $^{910}$ and other drugs. ${ }^{49} 52111$

\section{REINFORCING FACTORS}

In considering reinforcing factors, a distinction must be made between factors that reinforce the likelihood of suicidal behaviour, and those that may reinforce or support alternative, positive coping behaviours. Depression and suicide are associated with each other and with the absence of positive influences. ${ }^{112}$ The environmental diagnosis suggest that native persons are less likely to experience the positive rewards associated with success in school or a job that is common in the dominant culture.

\section{ENABLING FACTORS}

Suicides may be fostered by the presentation of violence and suicides on television and the ready availability of firearms and alcohol. The extensive general population literature examining the relationship between viewing television violence and the exhibition of aggressive behaviour supports the hypotheses that the viewing of violence leads to a desensitization to the negative effects of violence, the greater acceptance of violent normative behaviour, and the modelling of new forms of violence. ${ }^{113}$ As native adolescents are more likely to be unemployed, and have more time to view television, they are likely to be exposed to more violence than persons in full time employment. Studies of the specific effects of viewing suicides on television lead to the conclusion that stories of real suicides have a major effect on the frequency of suicide in the surrounding geographical area immediately after the broadcast, ${ }^{114-116}$ although there is some doubt about the modelling effect of fictional suicides. ${ }^{117} 118$

Firearms increase the likelihood of successful suicides. In 1988, 1372 American adolescents aged 13 to 19 used firearms to commit suicide. The problem is not restricted to handguns, as rifles and shotguns can be more lethal weapons than handguns. In the absence of firearms, adolescents may find it more difficult to commit suicide. ${ }^{119}$ For example, in a case-control study of 47 suicide victims, 47 parasuicides and 47 controls, it was found that guns were twice as frequently found in the homes of the suicides as in the homes of the parasuicides or controls. ${ }^{120121}$ The availability/ accessibility of firearms may enable suicidal behaviour.

Alcohol can have a number of different effects. It may lead to rejection from the family or tribal group. As a depressant drug, alcohol use may precipitate a predisposition to suicide. Research is consistent in showing that suicide is related to abuse of alcohol. ${ }^{505254}{ }^{69}$ Although the relationship between alcohol use and suicide among indigenous persons is commonly found, the interpretation of this relationship requires careful consideration, as the role of alcohol in depression and suicide is perceived differently by indigenous adolescents than by non-indigenous researchers. ${ }^{122}$ Within Australian Aboriginal communities, alcohol has had a major impact in the high prevalence of suicide. Since the use of alcohol by Aboriginals was legalized there has been a change in attitudes and expectations relating to alcohol, with excessive drinking being seen as a normative behaviour and many fathers are absent due to drinking. Frequently, these are the families where suicides are more common. ${ }^{36}$ Alcohol may also underlie many offences for which Aboriginal persons are incarcerated, thus having an indirect effect on the numbers of Aboriginal suicides while in police custody. ${ }^{123-126}$

\section{Administrative and policy diagnosis}

Whatever the choice of channel or target/ strategy of change, any health promotion program that hopes to change suicide related behaviours, lifestyles, or the environment must also undergo an administrative and policy diagnosis. At this stage, the program planner and program participants must assess the challenges, barriers, and obstacles to successful program implementation. People often point to the apparently abundant financial resources which governments make available to indigenous programs. Many communities are unaware of their existence however, or of the means of tapping them. Professionals attempting to assist in the development of programs are generally members of the dominant culture and often fail to understand the nature of native culture(s). ${ }^{98}$ For example, programs attempting to improve or ameliorate the socioeconomic conditions of indigenous persons have common difficulties. Financial resources available to develop industries seldom result in development of on-going industries to provide employment because the funding usually comes in the form of short term grants requiring short term visible benefits. This means that work projects are ad hoc, starting when there is funding and ceasing when the funding ends. Leaders are under pressure to produce visible effects with available funding leading to a focus on short term results at the expense of long term or culturally sensitive planning. ${ }^{98}$ As professionals are usually only short term residents in the community, they often lack a longer term perspective and an awareness of local concerns.

Further, projects designed to meet the requirements of the funding bodies, rather than those of the community, are often not sustainable. Competition between different programs for limited resources ${ }^{80}$ may lead to fragmentation of resources that might be used more effectively if allocated on a community, rather than a program, basis. Funding requirements lead to the development of programs imposed by professionals rather than those 
developed by the communities to meet their own needs. The problem is exacerbated by the belief that projects should have measurable outcomes, whereas, for short term projects, it would be more realistic to focus on process evaluations. Any community behavioural change occurs gradually over time, with successive increments of change needing to take place before there are assessable differences in mortality or morbidity.

This approach contrasts with the exceptional situation in the North Island of New Zealand ${ }^{32}$ where there is an emphasis on the importance of the Maori culture as a major source of tourist revenue. Many Maoris have stable jobs in the tourist industry where they use their cultural heritage to provide crafts and entertainment. Through the tourist industry their cultural heritage is being preserved and respected, and a sound economic base is being developed. Consistent themes emerge in relation to the administrative and policy diagnosis, although the evidence is more sparse and less clearly documented than that relating to other areas. Interventions are more likely to be successful if they are conducted on a community basis, on the initiative of the members of the community, and owned by them.

\section{Conclusion}

There is an extensive literature addressing different aspects of the environment of native persons. The consistency across continents supports Durkheim's observation that social environments are a major, if not the major, factor underlying suicide. Some social conditions are associated with a set of psychosocial factors that are in turn related to suicide. As there are more indigenous than non-indigenous persons who experience these social conditions, there are more indigenous persons reported as suicides. However, the causal variable is the social conditions of the people whose suicidal behaviour is being assessed, not their racial origins per se.

Indigenous persons are more frequently located in the lower strata of the social hierarchy than non-indigenous persons. This position in the social hierarchy has two types of effects: first, it influences social opportunities in relation to objective indices such as educational opportunities, employment opportunities, and disposable income; second, it influences the individual's self perception and hence their self esteem. Thus the environmental factors underlying suicide involve the position in the socioeconomic structure and cultural disintegration, both of which are a product of the impact of European settlement and the resultant relocation of indigenous persons onto selected, poorer areas, as well as the lack of recognition of the validity of their cultural heritage. ${ }^{115}$

These factors may combine to negatively effect family cohesiveness and the development of self worth. Thus any assessment of the role of behaviour, lifestyle, and environment in aboriginal suicide also needs to focus on the relations between indigenous cultures and the acculturation of natives to the predominant Western culture. Although there is more research in relation to the United States than Canada, Australia or New Zealand, the pat $\overline{\overline{3}}$ terns which occur across these different peoples have sufficient similarity to conclude tha $\bar{\Phi}$ suicide is more common among adolescent: males than other sections of the community Many of the factors underlying native adolese cent suicide can be connected to the undere mining of native culture and the placing os indigenous adolescents in physical, social, and economic environments which provide feves expectations of positive outcomes.

We are indebted to the Medical Services Branch of Healthw Canada for financial support of this review, and to Dawne Milligan for her work as a research assistant. The first authoo was a visiting scholar at the Institute of Health Promotion Research, University of British Columbia at the time this revievo was prepared.

1 Brown R, Ourunanjappa B, Hawk R, Bitsuic D. The epidemiology of accidents among the Navajo Indians? Public Health Rep 1970; 85: 881-8.

2 Simpson $S$, Reid $R$, Baker $S$, Teret $S$. Injuries among the Hopi Indians. $\mathfrak{f} A M A$ 1983; 249: $1873-6$

3 Egger G, Sleet D. Injuries amongst Aboriginal peopled Injury in Australia. South Australia: National Injury Injury in Australia. South Australia: National Injury Surveillance Unit, Australian Institute of Health ande

4 Berlin I. Suicide among American Indian adolescents: an overview. Suicide Life Threat Behav 1987; 17: 218-32. C 5 Hogg R. Indigenous mortality: placing Australian Abori ginal mortality within a broader context. Soc Sci Met 1992; 35: $335-46$.

6 Lamarine R. Alcohol abuse among Native Americans. Community Health 1988; 13: 143-54.

7 Oetting E, Edwards R, Beauvais F. Drugs and Native American youth. Drugs Society 1989; 3: 5-38.

8 Health Canada. Suicide in Canada: update of the report of the task force on sucide in Canada. Ottawa Ontario: lask force on suicide in Canada. Ottawa, Ontario: Mentat Health Division, Health Services Directorate, Health Programs and Services Branch, Health Canada, 1994.
Ennis J. Self harm: 1. Suicide. Can Med Assoc $\mathcal{7} 1983 ; 129$. $21-7$.

10 Ennis J. Self harm. 2. Deliberate non-fatal self-harm. Cañ Med Assoc f 1983; 129: $121-5$.

11 Green L, Kreuter M. Health promotion planning: a eductional and environmental approach. 2nd Ed. Toronto? Mayfield Publishing Company, 1991.

12 Gielen A. Health education and injury control-integrate ing approaches. Health Educ $Q$ 1992; 191: 203-18.

13 Gielen A, Radius S. Project KISS (kids in safety belts) educational approaches and evaluation measures. Healt

14 Dedobbeleer N, German P. Safety practices in construc tion industry. F Occup Med 1987; 29: 863-8.

15 National Committee for Injury Prevention and Controp Injury prevention: meeting the challenge. Am $\mathcal{f}$ Prev Me 1989; 5 (3 Suppl): $1-303$.

16 Sleet D. Health education approaches to motor vehiclo injury prevention. Public Health Rep 1987; 102: 606-8. I

17 Jones C, Macrina D. Using the PRECEDE model to design and implement a bicycle helmet campaign. Wele ness Perspectives 1993; 9: 68-95.

18 Wortel E, Gerard H, Kok G, van Woerkum C. Injur. control in pre-school children: a review of parental safetx measures and the behavioural determinants. Health EdrC Res 1994; 9: $201-13$.

19 Ajzen I, Fishbein M. Understanding attitudes and predicting social behaviour. Englewood Cliffs, NJ: Prentice Hale social

20 Becker H, Maiman L. Social behavioral determinants of compliance with health and medical care recommende䁬 tions. Med Care 1975; 13: $10-24$

21 Becker $M$. The health belief model and personal healti behaviour. Health Education Monographs 1974; 2: 4.

22 Frankish C. Crisis centers and their role in treatmen suicide prevention versus health promotion. Suicids assessment and intervention. Death Studies 1994; 18; 327-39.

23 Sigurdson E, Staley D, Matas M, Hildahl K, Squair K. five year review of youth suicide in Manitoba. Can Psychiatry 1994; 39: 397-403.

24 Yuen N, Andrade N, Nahulu L, et al. The rate an characteristics of suicide attempters in the native Hawas ian adolescent population. Suicide Life Threat Behav 1996 26: $27-36$.

25 Zitzow D, Desjarlait F. A study of suicide attempts comparing adolescents to adults on a northern plains American Indian reservation. Am Indian Alsk Native Ment American Indian reservation.

26 May P. Suicide and self-destruction among American Indian youths. Am Indian Alsk Native Ment Health Res 1987; 1: 52-69. 
27 May P. A bibliography on suicide and suicide attempts among American Indians and Alaska natives. Omega 1990; 21: 199-214.

28 Berlin I. Prevention of adolescent suicide among native American tribes. Adolesc Psychiatry 1985; 12: 77-93.

29 Chapdelaine A, Sainson E, Viau L. Firearm-related injuries in Canada: issues for prevention. Can Med Assoc f 1993; 145: 1217-23.

30 British Columbia Division of Vital Statistics. Morbidity and mortality indicators. Vancouver, BC: Ministry of Health 1991.

31 Husain S. Current perspectives on the role of psychosocial factors in adolescent suicide. Psychiatry Ann 1990; 20: $122-4,27$

32 Lester D. Maori and nonMaori youth suicide. N Z Med f 1994; 107: 161 .

33 Hunter E. Conflicting constructions of aboriginal suicideresponse. Aust NZ $\Im$ Psychiatry 1995; 29: 335-7.

34 Hunter E. Out of sight, out of mind-1. Emergent patterns of self-harm among aborigines of remote Australia. Soc Sci Med 1991; 33: 655-9.

35 Hunter E. Out of sight, out of mind-2. Social and historical contexts of self-harmful behaviour among aborigines of remote Australia. Soc Sci Med 1991; 33: 661-71.

36 Hunter E. Using a socio-historical frame to analyze aboriginal self-destructive behaviour. Aust $N Z$ f Psychiatry 1990; 24: $191-8$.

37 Hunter E. Aboriginal suicides in custody: a view from the Kimberley. Aust N Z F Psychiatry 1988; 22: 273-82.

38 Hunter $E$. An examination of recent suicides in remote Australia: Further information from the Kimberley. Aust $N Z$ F Psychiatry 1991; 25: 197-202.

39 Hunter E. On gordian knots and nooses: aboriginal suicide in the Kimberley. Aust NZ F Psychiatry 1988; 22: 264-71.

40 Hunter $E$. The social and family context of aboriginal selfharmful behaviour in remote Australia Aust $N Z \mathcal{Z}$ Psychiatry 1991; 25: 203-9.

41 Young T, Moffatt $M$, O’Neill J. An epidemiological perspective on injuries in the Northwest Territories. Arctic Med Res 1992; 51: $27-36$.

42 Van Winkle N, May P. An update on American Indian suicide in New Mexico, 1980-1987. Human Organization 1993; 52: 304-15.

43 Wallace L, Calhoun A, Powell K, O'Neill J, James S. Homicide and suicide among Native Americans 1979-1992. Atlanta: CDC, National Center for Injury Prevention and Control, 1996.

44 Thompson $T$. Childhood and adolescent suicide in Manitoba: a demographic study. Can $\mathcal{F}$ Psychiatry 1987 32: $264-9$.

45 Aldridge $\mathrm{D}$, St John $\mathrm{K}$. Adolescent and pre-adolescent suicide in Newfoundland and Labrador. Can $\mathcal{Y}$ Psychiatry 1991; 36: 432-6.

46 Anonymous. Suicide and ethnicity in the United States. Committee on Cultural Psychiatry. Group for the Advancement of Psychiatry. Report from the Group fo the Advancement of Psychiatry 1989; 128: 1-131.

47 Young T, French L. Status integration and suicide among Native American women. Social Behav Pers 1995; 23: $155-7$.

48 US Department of Health and Human Services. Healthy people 2000. National health promotion and disease prevention objectives. Washington, DC: Department of Health and Human Services, 1991 .

49 Blum $R$, Harmon B, Harris L, Bergeisen L, Resnick M American Indian-Alaska Native youth health. $\mathfrak{f} A M A$ 1992; 25: $1637-44$.

50 Grossman D, Milligan C, Deyo R. Risk factors for suicide attempts among Navajo adolescents. Am $\mathcal{F}$ Public Health 1991; 81: 870-4.

51 Gartrell J, Jarvis G, Derksen L. Suicidality among adolescent Alberta Indians. Suicide Life Threat Behav 1993; 23: 366-73.

52 Howard-Pitney B, LaFromboise T, Basil M, September B, Johnson $M$. Psychological and social indicators of suicide ideation and suicide attempts in Zuni adolescents. $f$ Consult Clin Psychol 1992; 60: 473-6.

53 Kettl P, Bixler E. Alcohol and suicide in Alaska natives. Am Indian Alsk Nat Ment Health Res 1993; 5: 34-45.

54 Manson S, Beals J, Dick R, Duclos C. Risk factors for suicide among Indian adolescents at a boarding school. Public Health Rep 1989; 104: 609-14.

55 Michalek A, Mahoney M, Buck G, Snyder R. Mortality patterns among the youth of a northeastern American Indian cohort. Public Health Rep 1993; 108: 403-7.

56 Hisnanick J. Comparative analysis of violent deaths in American Indians and Alaska Natives. Social Biol 1994 41: $96-109$.

57 Hlady W, Middaugh J. The underrecording of suicides in state and national records, Alaska, 1983-1984. Suicide Life Threat Behav 1988; 18: 237-44.

58 Lester D. Native American suicide and homicide rates: are they associated with white suicide and homicide rates? Psychol Rep 1994; 74: 702 .

59 Heacock D. Suicidal behaviour in black and Hispanic youth. Psychiatry Ann 1990; 20: 134-42.

60 Davenport J, Davenport J. Native American suicide: a Durkheimian analysis. Social Casework 1987; 68: 533-9.

61 Kposowa A, Breault K, Singh G. White male suicide in the United States-a multivariate individual-level analysis. Social Forces 1995; 74: 315-25.

62 Singh G, Yu S. Trends and differentials in adolescent and young adult mortality in the United States, 1950 through 1993. Am F Public Health 1996; 86: 560-4

63 Singh G, Yu S. US childhood mortality, 1950 through 1993-trends and socioeconomic differentials. Am $\mathcal{f}$ Public Health 1993; 86: 505-12.

64 Young T. Suicide and homicide among Native Americans: anomie or social learning? Psychol Rep 1991; 68: 1137-8.

65 Eastwell $H$. The low risk of suicide among the Yolngu of the Northem Territory: the traditional aboriginal pattern. Med F Aust 1988; 148: 338-40.

66 Mao Y, Moloughney B, Semenciw R, Morrison H. Indian reserve and registered Indian mortality in Canada. Can $\mathcal{f}$ Public Health 1992; 83: 350-53.

67 LaFromboise T, Bigfoot D. Cultural and cognitive considerations in the prevention of American Indian adolescent suicide. F. Adolesc 1988; 11: 139-53.

68 Long K. Suicide intervention and prevention with Indian adolescent populations. Issues in Mental Health Nursing 1986; 8: $247-53$

69 Levy J, Kunitz S. A suicide prevention program for Hopi youth. Soc Sci Med 1987; 25: $931-40$.

70 Dacks G. Worker-controlled native enterprises: a vehicle for community development in Northern Canada? Can $\mathcal{F}$ Native Stud 1983; 3: 289-310.

71 Erikson E. Childhood and society. New York: Norton, 1950.

72 Erikson E. Identity, youth and crisis. New York: Norton, 1968.

73 Teicher J. Suicide and suicide attempts. In: Noshpitz J, ed. Basic handbook of child psychiatry. New York: Basic Books, 1979.

74 Swedo S, Rettew D, Kuppenheimer R, Lum D, Dolan S, Goldenberger E. Can adolescent suicide attempters be distinguished from at-risk adolescents? Pediatrics 1991; 88: $620-9$.

75 Roberts I, Pless B. Social policy as a cause of childhood accidents: the children of lone mothers. BMF 1995; 311: 925-8.

76 Dizmang L, Watson J, May P, Bopp J. Adolescent suicide at an Indian reservation. Am $\mathcal{f}$ Orthopsychiatry 1972; 44: 43-9.

77 Dinges N, Duong-Tran Q. Suicide ideation and suicide attempt among American Indian and Alaska Native boarding school adolescents. Am Indian Alsk Native Men Health Res 1994; 4: 167-88.

78 Sack W, Beiser M, Phillips N, Baker-Brown G. Co-morbid symptoms of depression and conduct disorder in First Nations children: some findings from the Flower of Two Soils Project. Culture Med Psychiatry 1992; 16: 471-86.

79 Sack W, Beiser M. Depressive and suicidal symptoms in Indian school children: findings from the Flower of Two Soils. Am Indian Alsk Native Ment Health Res 1994; 4: $81-96$.

80 Beauvais F, LaBoueff S. Drug and alcohol abuse interventions in American Indian communities. Int $\mathcal{f}$ Addict 1985; 20: 139-71.

81 Lester D. Suicide rates in Canadian aboriginals and size of population. Percept Mot Skills 1995; 81: 1282.

82 Lester D. Suicide rates in Native Americans by state and size of population. Percept Mot Skills 1994; 78: 954

83 Wolfenden K, Clarke L, Lower T, Murray-Jones S. Rural child injury prevention-a community-based approach. Health Promotion fournal of Australia 1991; 1: 23-7.

84 Bagley C. Poverty and suicide among Native Canadians: a replication. Psychol Rep 1991; 69: 149-50.

85 Shah C, Farkas C. The health of Indians in Canadian cities: a challenge to the health care system. Can Med Assoc f 1995; 133: 859-63.

86 Shah C, Kahan M, Krauser J. The health of children of low-income families. Can Med Assoc f 1987; 137: 485-

87 Young T, French L. Suicide and social status among Native Americans. Psychol Rep 1993; 73: 461-2.

88 Young T. Poverty, suicide, and homicide among Native Americans. Psychol Rep 1990; 67: 1153-54.

89 Durkheim E. Suicide. New York: Free Press, 1951.

90 Pillay A, Wassenaar D. Psychological intervention, spontaneous remission, hopelessness and psychiatric disturbance in adolescent parasuicides. Suicide Life Threat Behav 1995; 25: 386-92.

91 Lester D. Patterns of suicide and homicide in America. Commack, NY: Nova Science Publishers, 1994.

92 Westermeyer J. Alcoholism among New World peoples-a critique of history, methods, and findings. Am $\mathcal{f}$ Addict critique of history,

93 Young T. Native American drinking: a neglected subject of study and research. $\mathcal{F}$ Drug Educ 1991; 21 : 65-72.

94 Recce $R$, Grodin $M$. Recognition of non-accidental injuries. Pediatr Clin North Am 1985; 32: 41-60.

$95 \mathrm{Kahn} \mathrm{M,} \mathrm{Lejero} \mathrm{L,} \mathrm{Antone} \mathrm{M,} \mathrm{Francisco} \mathrm{D,} \mathrm{Manuel} \mathrm{J.} \mathrm{An}$ indigenous community mental health service on the Tohono O'odham (Papago) Indian Reservation: seventeen years later. Am f Community Psychol 1988; 16: 36979.

96 Newberger E. The helping hand strikes again: unintended consequences of child abuse reporting. $f$ Clin Child Psychol 1993; 12: 309-15.

97 Charles G. Suicide intervention and prevention among northern Native youth. $\mathcal{F}$ Child Youth Care 1991; 6: 11 -7.

98 Erasmus P, Ensign J. A practical framework for community liaison work in native communities. Injury Awareness and Prevention News 1992.

99 Hlady W, Middaugh J. Suicides in Alaska: firearms and alcohol. Am f Public Health 1988; 78: $179-80$

100 Indian and Northern Affairs Canada Task Force. Indian economic development. Report to the Deputy Minister, Indian and Northern Affairs, 16 December 1985, Ottawa, Ontario: Ministry of Indian Affairs and Northern Development, 1987. 
101 Jarvis O, Boldt $M$. Death styles among Canadian Indians. Soc Sci Med 1992; 16: 1345-52.

102 Dinges N, Duong-Tran Q. Stressful life events and cooccurring depression, substance abuse and suicidality occurring depression, substance abuse and suicidality among American Indian and Alaska Native

103 Cooper M, Corrado R. Aboriginal suicide in British Columbia: an overview. Can Ment Health 1992; 40: 1923.

104 Morrell S, Taylor R, Qunic S, Kerr C. Suicide and unemployment in Australia 1907-1990. Soc Sci Med 1993; 36: 749-56.

105 Bechtold D. Cluster suicide in American Indian adolescents. Am Indian Alsk Native Ment Health Res 1988; 1: 26-35.

106 Bechtold D. Indian adolescent suicide: clinical and developmental considerations. Am Indian Alsk Native Ment Health Res 1994; 4: 71-80.

107 Rodgers D. Community crisis intervention in suicide Rodgers D. Community crisis intervention in

108 Tower M. A suicide epidemic in an American Indian community. Am Indian Alsk Native Ment Health Res 1994; 3: $34-44$.

109 Clayer J, Czechowicz A. Suicide by aboriginal people in South Australia. Med $\mathcal{f}$ Aust 1991; 154: 683-5.

110 O'Neill T. 'Feeling worthless': an ethnographic investigation of depression and problem drinking at the Flathead Reservation. Culture Med Psychiatry 1992; 316: 447-69.

111 Liu L, Slap G, Kinsman S, Khalid N. Pregnancy among American Indian adolescents: reactions and prenatal care. f Adolesc Health 1994; 15: 336-41.

112 Harvey E. Mental health promotion among American Indian children. Arctic Med Res 1995; 54: $101-6$

113 Waters D. Networks under the gun. Newsweek 1993, July $12 ; 64-6$.

114 Phillips D, Caratensen L. Clustering of teenage suicides after television news stories about suicide. $N$ Engl $\mathcal{F}$ Med
1986; 315: 685-9.

115 Phillips $\mathrm{D}$, Paight $\mathrm{D}$. The impact of televised movies about suicide: a replicative study. $N$ Engl f $\mathrm{Med}$ 1987; 317: $809-11$

116 Phillips D. The influence of suggestion on suicide: substantive and theoretical implications of the Werti effect. Am Sociological Rev 1974; 39: 340-54.

117 Gould M, Schaffer D. The impact of suicide in television movies: evidence of imitation. $N$ Engl f Med 1986; 319 690-4.

118 Stack C. Celebrities and suicide: a taxonomy and analys 1948-1983. Am Sociological Rev 1987; 52: 401-12. O 19 Rosenberg M, Mercy J, Houk V. Guns and adolesce suicides. fAMA 1991; 4: 3030.

120 Brent D, Perper J, Allman C, Moritz G, Wartella $\bar{M}$ Zelenak $T$. The presence and accessibility of firearms the homes of adolescent suicides. FAMA 1991; 266 $2989-95$.

121 Becker T Samet J Wiggins C Key C Violent death in th west: suicide and homicide in New Mexico, 1958-198\%? Suicide Life Threat Behav 1990; 20: 324-34.

122 Bouchard L. Suicides in the Quebec and Chaudiere-Appataches regions: a multifactorial approach for suicide prevention. The Second World Conference on Injury Contrody Atlanta, GA, May 1993.

123 Lawlor D, Kosky R. Serious suicide attempts amono adolescents in custody. Aust $N Z \mathcal{F}$ Psychiatry 1993; 26: 474-78.

124 McDonald D, Thomson N. Australian deaths in custod 1980-1989. Med f Aust 1993; 159: 581 - 5

125 Bland R, Newman S, Dyck R, Orn H. Prevalence of psychiatric disorders and suicide attempts in a prisos
population. Can $\mathcal{P}$ Psychiatry 1990; 35: 407-13.

126 Duclos C, LeBeau W. American Indian adolescent suicide behaviour in detention environments: cause for continueit basic and applied research. Am Indian Alsk Native Ment Health Res 1994; 4: 189-221.

\section{Editorial Board Member: brief biography}

\section{POLLY BIJUR}

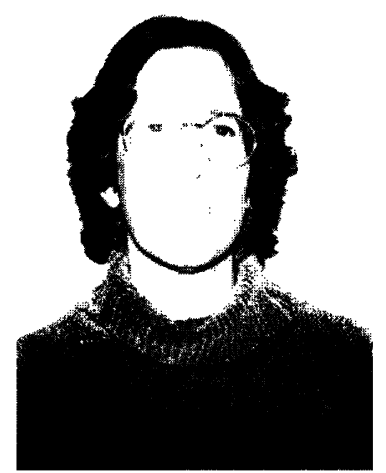

Polly Bijur, $\mathrm{PhD}, \mathrm{MPH}$ is Professor of Pediatrics and Epidemiology/Social Medicine at Albert Einstein College of Medicine, Bronx, New York. She is the Director of the Division of Epidemiology within the Department of Pediatrics.

Dr Bijur received master's level training in biostatistics at the Columbia University School of Public Health and doctoral training in epidemiology from Columbia University. She was the recipient of a National Institute of Mental Health fellowship in psychiatric epidemiology between 1977 and 1983. She has been a member of the faculty at Albert Einstein College of Medicine since 1983.

Her research has focused on the psychological and social characteristics of children and their families that contribute to risk of injury and has also examined the psychosocial sequelae of injuries. She has carried out descriptive analyses of athletic injuries both in the general US population and in the US military.

In addition to research, Dr Bijur teaches research methods to pediatric fellows and clinical epidemiology to medical students. She also provides consultation to faculty and fellows within the Department of Pediatrics on research design, measurement, and data analysis. She has been a member of a Special Emphasis Panel of the NIH study section-Epidemiology and Disease Control I since 1993 and is a scientific advisor to the Epidemiology Branch, Division of Epidemiology, Statistics, and Prevention Research at NICHD. 